\title{
Kenia: Ofrezca servicios de planificación familiar en salas hospitalarias
}

Frontiers in Reproductive Health

Follow this and additional works at: https://knowledgecommons.popcouncil.org/departments_sbsr-rh

Part of the Health Services Research Commons, International Public Health Commons, and the Women's Health Commons

How does access to this work benefit you? Let us know!

\section{Recommended Citation}

"Kenia: Ofrezca servicios de planificación familiar en salas hospitalarias," FRONTERAS Resúmenes de Investigación Operativa. Ciudad de México: Population Council, 2000. 


\section{Kenia Atención postaborto}

\section{Resumen de $1 \mathrm{O} 4$}

\title{
Ofrezca servicios de planificación familiar en salas hospitalarias
}

\begin{abstract}
La manera más eficaz de asegurar que las mujeres que están bajo tratamiento debido a un aborto incompleto obtengan servicios de planificación familiar, es ofrecerles información y atención en las salas de ginecología del hospital. Es más conveniente que el personal de estas salas proporcione anticonceptivos a las pacientes en vez de que los proveedores de planificación familiar las visiten con ese fin o les pidan que acudan a otra clínica. Los hallazgos de este estudio han sido clave para dar a conocer el plan de expansión de la atención postaborto
\end{abstract} (APA) en Kenia.

\section{Antecedentes}

En Kenia, más de un tercio de las mujeres hospitalizadas por problemas ginecológicos padecen complicaciones ocasionadas por un aborto espontáneo o inducido. Por lo general, estas mujeres no reciben información o servicios de planificación familiar, ni atención para otras necesidades de salud reproductiva.

Entre 1996 y 1997, el Ministerio de Salud (MS) de Kenia, el Population Council e Ipas colaboraron para probar tres modelos de APA y de información y servicios de planificación familiar (PF) en dos áreas del hospital. Dichos modelos son: (1) prestación de servicios de PF postaborto por parte del personal de las salas ginecológicas, dentro de las mismas; (2) provisión de PF por parte del personal de la clínica de atención materno-infantil (MI)/PF en la sala de ginecología, y (3) prestación de servicios de PF en la clínica de atención MI/PF después de recibir atención postaborto pero antes del alta hospitalaria. Seis grandes hospitales de distrito y provinciales sirvieron como centros experimentales. Los investigadores compararon la efectividad de los tres modelos mediante el uso de encuestas que se aplicaron antes (a 481 pacientes y 140 proveedores) y después de la intervención (a 319 pacientes, 92 compañeros o esposos de las pacientes y a 106 proveedores). La intervención consistió en: (1) capacitación a médicos y enfermeras en la técnica de aspiración manual endouterina (AMEU) y PF postaborto; (2) abastecimiento de equipo y consumibles, y (3) reorganización de los servicios para satisfacer mejor

Gráfica1. Mujeres que recibieron consejería y métodos de PF

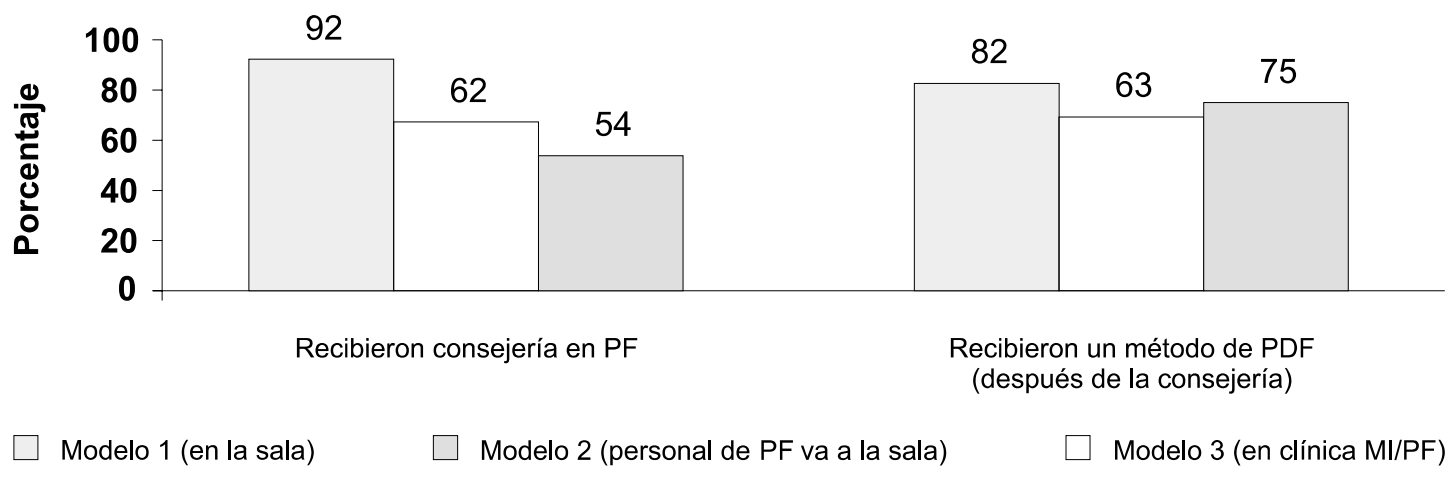


las necesidades de las pacientes. Todos los centros experimentales designaron salas pequeñas para la realización de la AMEU, con lo que agilizaron el flujo de pacientes y liberaron los quirófanos principales. Los hospitales que ofrecen servicios de PF crearon áreas privadas para consejería dentro de las salas, al instalar separaciones y reutilizar espacios. Los anticonceptivos se obtuvieron de la clínica de MI/PF del hospital.

\section{Resultados}

Modelo 1. Brindar información y servicios PF postaborto en la sala de ginecología aumentó el uso de anticonceptivos y acortó la estancia hospitalaria. Con este modelo, un número mayor de pacientes recibió de manera efectiva la consejería y los servicios de PF en comparación con los otros dos modelos (véase Gráfica 1).

Tanto los proveedores como los pacientes reaccionaron favorablemente a los servicios mejorados de APA en los tres modelos. Los proveedores prefirieron la AMEU a las otras técnicas clínicas practicadas antes de la intervención. Antes de la introducción del paquete, únicamente el siete por ciento de todas las pacientes de APA recibía consejería en planificación familiar, mientras que después de la intervención este porcentaje se elevó a 68 por ciento.

- En todos los sitios, los servicios de APA se podrían mejorar aún más si se diera a las pacientes mayor información. Únicamente el 16 por ciento de las pacientes recibió información sobre qué hacer si se presentaba algún problema. De igual manera, sólo al 41 por ciento de las pacientes se les advirtió sobre la posibilidad de volver a concebir poco después del aborto. Cerca de la mitad de las pacientes recibió información acerca de los posibles efectos secundarios del método elegido.

Las prácticas para el control del dolor siguen siendo un problema. Solamente el 3 por ciento de las pacientes en el grupo de línea basal y en el de postintervención recibieron medicamentos para calmar el dolor; por consiguiente, casi todas las mujeres reportaron haber tenido dolor durante el tratamiento.

Los esposos/compañeros de las pacientes manifestaron un gran interés en recibir más información de parte de los proveedores. Más del 90 por ciento de los hombres entrevistados dijeron que les habría gustado saber más acerca del estado de su esposa/compañera, así como de planificación familiar. Un hospital empezó a dar consejería a parejas en la sala de ginecología.

\section{Implicaciones normativas}

El personal de las salas de ginecología debe ofrecer información y servicios de PF postaborto en dichas salas. Es posible que el personal requiriera capacitación adicional para dar consejería en PF.

Los hombres que acompañan a las pacientes de APA deberían recibir también información sobre el estado de sus compañeras así como consejería en PF, si es que la mujer da su consentimiento.

Los proveedores de APA deben administrar medicamentos para controlar el dolor y no depender únicamente del apoyo verbal que puedan brindar a las pacientes.

Para garantizar la continuidad de los servicios de APA, los administradores de hospitales necesitan asegurarse de que el personal esté capacitado adecuadamente y de que se cuente con el equipo, los consumibles y los medicamentos. Asimismo, se requiere capacitación previa y en servicio para integrar la APA al sistema de salud actual.

Con base en estos hallazgos, el MS de Kenia elaboró planes de trabajo detallados para la expansión de los servicios mejorados de APA. Tales planes se han incorporado ya a una estrategia nacional de expansión de APA, tanto en el sector publico como en el privado.

Febrero 2000

Solo, Julie, et al. 1998. Creating Linkages between Incomplete Abortion Treatment and Family Planning Services in Kenya: What Works Best? Véase también: Improving Care of Postabortion Patients in Hospitals, OR Summaries, January 1998. Para obtener más información escriba o llame a: Population Council-Oficina Regional para América Latina y el Caribe. Escondida 110, Villa Coyoacán, 04000, México, D.F. México. Tel. (52) 55-54-03-88; Fax: (52) 55-54-12-26. Correo electrónico: disemina@ popcouncil.org.mx.

Este proyecto fue posible gracias al apoyo de la Agencia de los Estados Unidos para el Desarrollo Internacional (USAID) bajo el contrato número CCP-3030-C-00-3008-00 y el Acuerdo de Cooperación número HRN-A-00-98-00012-00 